\title{
Comentários pertinentes sobre usos de metodologias qualitativas em saúde coletiva
}

Mara Helena de Andréa Gomes(a)

Denise Martin ${ }^{(b)}$

Cássio Silveira(c)

Gomes MHA, Martin D, Silveira C. Pertinent comments about the use of qualitative methodologies in the public health field. Interface (Botucatu). 2014; 18(50):469-77.

This paper aims to contribute towards assessing production and dissemination of research based on qualitative methodologies within the field of public health. We sought to correlate the theoretical and methodological gaps with indicative values that traverse the processes of research and evaluation of published articles. In the absence of explicit statement of the values that lead to the choices intrinsic to research, some journals have recommended assessment resources that focus on formal technical procedures. Such assessments are complemented by guidelines for article compilation, including checklists of the items that are valued. These factors contribute towards theoretical and methodological reductionism and reinforce the idea that a single method exists. Lastly, we renew the appeal for imagination and diversity among the conceptions of matters that we desire to learn about.

Keywords: Qualitative research methodologies. Peer review. Public health. Social and human sciences.
Com este texto visamos contribuir para o debate sobre a avaliação da produção e divulgação de pesquisas que se baseiam em metodologias qualitativas no campo da saúde coletiva. Procuramos relacionar as lacunas teóricas e metodológicas a indícios valorativos que atravessam os processos de pesquisa e avaliação de artigos publicados. Na ausência de explicitação dos valores que conduziram às escolhas imbricadas nas pesquisas, alguns periódicos recomendam recursos de avaliação que privilegiam procedimentos formais e técnicos. A avaliação é complementada com guias de confecção de artigos, dentre os quais os check-lists, que fornecem os itens valorizados. Estes fatores contribuem para reducionismos teórico-metodológicos e reforçam a crença na existência de um único método. Por fim, renovamos o apelo à imaginação e à diversidade de concepções sobre o que pretendemos conhecer.

Palavras-chave: Metodologias de pesquisa qualitativa. Avaliação por pares. Saúde Pública. Ciências sociais e humanas.

\footnotetext{
(a,b) Departamento de Medicina Preventiva, Escola Paulista de Medicina, Universidade Federal de São Paulo. Rua Botucatu, 740,

$4^{\circ}$ andar. São Paulo, SP, Brasil. 04023-

900. maraandrea@ unifesp.br; denise.martin@ unifesp.br

(c) Departamento de Medicina Social, Faculdade de Ciências Médicas da Santa Casa de São Paulo. São Paulo, SP, Brasil. cassio.silveira@ fcmsantacasasp.edu.br
} 


\section{Introdução}

É notável a crescente importância da pesquisa qualitativa na área de Saúde Coletiva. Suas contribuições ao campo podem ser observadas na apresentação de estudos originais, realizados por meio de abordagens inovadoras proporcionadas por suas particularidades teórico-metodológicas. Tais "feitos" vêm sendo apontados nas últimas duas décadas, não sem certas preocupações.

Neste artigo queremos apontar a perspectiva relacional como importante requisito para realização de estudos qualitativos, com o objetivo de dar continuidade ao diálogo sobre produção interdisciplinar de conhecimento, tendo por referência nossas leituras não sistemáticas de artigos publicados e de nossa experiência como pareceristas em periódicos do campo da saúde coletiva. Para isso, convidamos o leitor a refletir sobre possíveis inconsistências teóricas e metodológicas observadas em algumas análises.

Com estes procedimentos, pretendemos contribuir para que a inserção das metodologias qualitativas ganhe força e contribua, no conjunto de conhecimentos produzidos em saúde coletiva, para a ampliação de um fazer ciência que seja, de fato, rigoroso e alicerçado em bases teóricas.

Comecemos por um elemento comum entre os enfoques particulares proporcionados pelas diferentes ciências sociais e humanas: a postura crítica em relação ao que pretendem analisar nos processos de pesquisa. A nosso ver, essa virtude presumida não se completa sem que os pesquisadores não apliquem a si próprios a crítica que desenvolvem em relação às situações que pretendem analisar. Desta crítica relação, de "tripla mão", instaurada pelo pesquisador - na sua relação entre aquilo que analisa e sua autoanálise como pesquisador, mediada pelas interações com outros pesquisadores -, resultam conflitos que dinamizam o processo de investigação.

Evidentemente, não reivindicamos essa crítica relação e os conflitos que engendram como prerrogativa das ciências sociais e humanas, posto que são comuns a qualquer campo de conhecimento. Mas, refletir sobre ela sob uma perspectiva relacional é (ou deveria ser) a condição de operar das chamadas "humanidades" quando falamos de metodologias de pesquisa qualitativa. Enfatizar esta condição indica, também, uma preocupação crescentemente compartilhada em relação a certas maneiras com que essas ciências vêm sendo absorvidas no campo da saúde coletiva. Aqui, queremos sinalizar algumas formas de pensar, de julgar e de opinar como indícios valorativos legítimos, diga-se - operados por pesquisadores, autores, especialistas ou peritos que contribuíram para tal propagação. Talvez, neste reconhecimento, esteja localizado o atributo que confere a particularidade reivindicada.

Em matéria de contribuição, uma presença tão marcante poderia ser motivo de comemorações, não fora a ausência de aportes teórico-críticos (sociais e históricos), na mesma proporção em que experiências tão diversas vêm sendo realizadas e publicadas.

Recentemente, Deslandes e Iriart ${ }^{1}$ mapearam usos teórico-metodológicos correntes nas pesquisas do subcampo das ciências sociais e humanas em saúde. Para estes autores, vários dos estudos analisados utilizam as técnicas de construção dos dados qualitativos de forma instrumental, caracterizando-se por um "empirismo a-teórico", e também ressaltam vários casos de artigos que fazem usos inadequados de certas categorias analíticas e, mesmo, de técnicas e métodos. Outros autores, como Nakamura ${ }^{2}$ e Victora ${ }^{3}$, já haviam ressaltado fatos que, juntamente com nossas leituras, tornaram possível afirmar que uma boa parte dos trabalhos publicados caracteriza-se por reproduzir, ainda que de maneira renovada do ponto de vista técnico e operacional, certos modos de pensar e fazer predominantes em outros campos de conhecimento.

No campo das ciências sociais em saúde, essas questões vêm sendo apontadas há mais de uma década por vários autores (por exemplo: Nunes ${ }^{4}$, Gomes $^{5}$, Luz ${ }^{6}$, Canesqui ${ }^{7}$, Martin et al. ${ }^{8}$, Gomes e Silveira ${ }^{9}$, Loyola ${ }^{10}$, Bosi ${ }^{11}$ e Minayo ${ }^{12}$ ), salientando os conflitos próprios e decorrentes das relações institucionais e acadêmicas, mesmo quando pesquisadores são bem intencionados na direção do convívio e de trocas interdisciplinares, como se espera no campo da saúde coletiva.

Entre muitos fatores, reconhecer essas condições de convívio e conflito conduz a indagar sobre a formação adequada de sujeitos pesquisadores. Uma formação que seja capaz de abarcar a densidade teórica e, simultaneamente, a generosidade necessária para compartilhar campos, conhecimentos e 
métodos de pesquisa. Significa supor que pesquisadores de áreas distintas se dispõem a conhecer e compartilhar conhecimentos no próprio processo e, assim, se constituírem como sujeitos críticos.

Talvez o estranhamento/descrédito em relação a pesquisas qualitativas no campo da saúde coletiva refira-se, compreensivelmente, à ausência de sustentação teórica e ao uso (muitas vezes, abusivo) de técnicas como se fossem métodos. Maingueneau ${ }^{13}$ organizou a produção de autores que lidam com análise qualitativa, por exemplo, em grupos distintos de pensamentos que convergem quanto a esses usos, e apontou temas transversos entre eles. Embora se refira mais especificamente ao numeroso grupo que utiliza a análise de discurso como "método qualitativo", é interessante a comparação que esta autora faz a respeito do uso de métodos como se estivessem disponíveis na "caixa de ferramentas" das ciências sociais e humanas.

Enfim, essa questão não é nova e assume feições renovadas. Em tocante editorial do importante periódico nacional Cadernos de Saúde Pública, as editoras se perguntam:

O que na verdade pretendemos com o texto científico? Que ele seja lido e que contribua, mesmo que modestamente, para a construção do conhecimento na área. Muitas vezes os autores esquecem que há um leitor ao final desse processo. A pressa para submeter o artigo torna os autores descuidados, o que, aliado à falta de prática e à pouca ajuda de pesquisadores mais experientes, traz para os editores e consultores a antipática tarefa de dizer: seu texto está muito ruim! ${ }^{14}$ (p. 1701)

Claro que as editoras não se referiram apenas a pesquisas qualitativas, mas, também, é claro que estão se referindo a abusos de diversos matizes: desde a própria confecção - descuidada - do texto, como a necessidade de experiência para a elaboração requerida por um texto publicável.

De onde falamos, ou seja, das ciências sociais e humanas, "alcançar a realidade" implica tempo e formação para que a 'realidade' seja 'alcançada'. Exige, portanto, amadurecimento intelectual. Embora requeira muito exercício, não se trata de um exercício ou tarefa para ser entregue ao final de um curso e se alcançar crédito. Neste último caso especialmente, contribui sim para o descrédito, como apontam, mais uma vez, Carvalho, Travassos e Coeli ${ }^{14}$.

Às vezes dizemos isso com o coração apertado: a ideia é inovadora, a quantidade de trabalho investido na coleta dos dados e estudo é imensa, e... o resultado final é quase ininteligível. Outras vezes, temos um artigo bem escrito, sem erros gramaticais, mas que se perde em detalhes de tal forma que no final não se consegue entender onde o autor pretendia chegar. E mais: textos com descompassos entre introdução e discussão, entre objetivos e métodos. Sem falar no resumo, talvez a peça mais essencial e mais negligenciada de todo o processo. Não é incomum recebermos em CSP artigos cujo resumo não deixa claro o conteúdo do manuscrito. (p. 1701)

A intensificação do ritmo da "produtividade" acadêmica aferida pela quantidade de artigos publicados a qualquer custo também motivou nossa reflexão. Diante da apresentação de resultados de pesquisas majoritariamente em formato de artigo, parte dos relatos das pesquisas qualitativas acaba acompanhando certa tendência reducionista, sob dois pontos de vista: seja quando as conclusões apresentadas reclamam, quase invariavelmente, por mais políticas públicas para as mais diversas finalidades; seja por prescreverem comportamentos adequados para que as desejadas políticas possam ser implantadas 5,15 . A salutar tradição do campo das humanidades de produzir relatos ampliados. com a apresentação do detalhamento dos procedimentos metodológicos enquanto experiência pessoal do sujeito investigador, a exposição de extensos conjuntos de material empírico que permitam ao leitor verificar horizontes e limites da observação produzida, além da reflexão construída no próprio processo de pesquisa que permita ao leitor apreender os modelos teóricos interpretativos sobre o processo social investigado, são procedimentos que deixaram de ocupar espaço (em número de páginas, inclusive) nos veículos de publicação constituídos pelos periódicos.

Se, por um lado, ganhamos com a agilidade de uma comunicação mais rápida e extensiva em seu alcance mundial, viabilizando a divulgação de nossas ideias em redes de bibliotecas virtuais (algumas 
mais acessíveis, outras nem tanto), por outro lado, corremos o risco de perder a abrangência de análises profícuas sobre os fenômenos sociais de maneira geral, e de saúde em particular.

Embora estas constatações estejam colocadas para o campo da saúde coletiva desde sempre, ainda nos surpreendemos com a açodada multiplicação de artigos nos quais já não nos reconhecemos como intelectuais de uma das áreas em relação, ao mesmo tempo em que não podemos nos reconhecer em outras. Uma vez que construímos nossas identidades acadêmicas e profissionais nessas relações, trata-se, então, de pensar novas modalidades de elaboração de pesquisas qualitativas que contemplem as possibilidades ofertadas pelas formações profissionais envolvidas nas práticas de saúde, ao mesmo tempo em que atentem para virtuais consequências dessas perdas e ganhos.

Considerando que praticamente todas as categorias profissionais da área da saúde são solicitadas a produzir artigos (nutrição/saúde alimentar, profissionais da saúde ambiental, educação física, direito/ direito sanitário, serviço social, enfermagem, técnicos de enfermagem, odontologia, fisioterapia, terapia ocupacional, psicologia, fonoaudiologia e medicina), as perdas podem ser relativizadas diante das possibilidades dos ganhos conquistados ao longo dos processos. Mas precisamos ficar atentos para os riscos de perda de inteligibilidade daquilo que produzimos.

\section{A dissonância entre modos de fazer pesquisa qualitativa: o exemplo do Guia RATS}

Iniciativas para ajudar o autor a avaliar se seu manuscrito poderá ser aceito pelos editores são sempre bem-vindas, geralmente pela via de um check-list dos periódicos, no item "informações aos autores". A necessária adequação ao formato do periódico é um caminho importante na submissão do artigo. Todavia, estas informações são somente orientações de ordem formal e estão muito distantes de uma proposta de avaliação crítica de um manuscrito.

O Guia RATS (Qualitative Research Review Guidelines) ${ }^{16}$ nos fornece um bom exercício de reflexão. Adotado por alguns periódicos como referência para revisar um estudo qualitativo, pretende, no nosso ponto de vista, orientar os autores a checar, minimamente, a estrutura de uma pesquisa qualitativa. Sua contribuição pode ser positiva, uma vez que pode guiar os autores menos experientes para que se cumpram todas as exigências para a submissão de um manuscrito de maneira coerente e clara.

O Guia abrange algumas etapas de construção formal de um estudo qualitativo: a relevância do estudo, se o método é adequado, se os procedimentos de amostragem foram adequados, como foram selecionados os participantes, se há informações sobre como foram coletados os dados, o papel dos pesquisadores, apresentação de resultados e ética. O Guia Rats chama a atenção dos avaliadores e dos autores interessados para a adequação do método qualitativo ao objetivo proposto, desde a seleção dos pesquisadores e participantes da investigação quanto ao conhecimento requerido para a pesquisa, até a justificativa adequada para o desenho que seguiu.

Vejamos um subitem do Guia Rats : o método. Por ser um guia, o texto é bem curto e traz itens em duas colunas: "pergunte isto ao manuscrito" (coluna A) e "isto deveria estar incluído no manuscrito" (coluna B), indicando o que supostamente deveria estar presente no texto.

Um dos itens trata da adequação do método qualitativo. Na coluna $A$, o guia sugere uma pergunta orientadora: A metodologia qualitativa é a melhor escolha para os objetivos do estudo? Em seguida, são citadas algumas alternativas, como: entrevistas (experiência, percepções, comportamento, prática, processos), grupos focais (dinâmica de grupo, conveniência, tópicos não sensíveis), etnografia (cultura, organização, comportamento e interação), análise textual (documentos, arte, representações, conversas). Na coluna B, sugere, portanto, que o desenho do estudo deve ser descrito e justificado, isto é, por que este método particular foi escolhido?

Faremos um breve exercício reflexivo sobre um estudo cujo método escolhido é o etnográfico. O que significa buscar palavras como cultura, organização, interação ou comportamento? O que elas dizem sobre o referencial teórico que as sustenta? A Antropologia possui inúmeros conceitos de cultura que, quando usados corretamente, mostram possibilidades distintas de interpretação dos dados coletados. Por exemplo, uma leitura de autores pós-modernos sobre a cultura é radicalmente diferente das várias leituras dos clássicos, que também se diferenciam entre si. Da mesma forma, como definir o comportamento? Trata-se de uma palavra tão polissêmica e utilizada por tantas áreas do conhecimento 
que qualquer definição ateórica a torna um elemento vazio, sem significado. O mesmo vale para as palavras organização e interação.

Supõe-se que o leitor do Guia tenha conhecimento dos itens citados ou, pelo menos, esteja ciente da necessidade de sustentação teórica de cada palavra citada. Afinal, guias são úteis para organizar ideias e não devem pretender, de modo algum, substituir textos mais densos ou teóricos. Os conceitos citados são muito mais exemplos dos itens que devem estar presentes no manuscrito. Do contrário, corre o risco de se tornar um modelo vazio que pode ser preenchido com tudo, sem nenhuma crítica ou teoria subjacente.

Chama a atenção também, neste item, a maneira pela qual as entrevistas, grupos focais, etnografia ou análise de texto são uniformemente citadas como técnicas. Vários pesquisadores vêm ressaltando esta confusão ou mal-entendido entre técnicas e métodos ${ }^{2}$ e, o mais preocupante, o uso de técnicas como se fossem métodos. De fato, o que nos preocupa é que o uso despreparado do Guia Rats desloque o cerne da questão que estamos apontando: não se trata de uma discussão sobre técnicas, mas sobre maneiras de se fazer ciência. Quando o avaliador ou pesquisador, seguindo inadvertidamente o guia, se atém somente à estrutura formal do artigo, incorre no risco de engessar a criatividade, o insight e o texto originais. Realizar um checklist por si só pode significar não ter argumentação substantiva sobre fazer ciência e, muito menos, sobre o imenso e vasto campo de produções de estudos compreensivo-interpretativos.

Poderíamos fazer este exercício com todos os itens citados no Guia, o que não invalidaria, necessariamente, sua utilidade para alguns. Nossa preocupação refere-se ao seu uso para avaliar estudos e julgá-los como se fossem ou não estudos qualitativos rigorosos e comprometidos com a ciência. De fato, não há nada de errado nele, muito pelo contrário. A apropriação superficial e inadequada dos métodos qualitativos por alguns pesquisadores tem confundido seu uso original, de ser somente um guia. Além disso, seu uso exclusivo revela desconhecimento da complexidade e profundidade teórica envolvida em estudos qualitativos. Em alguns casos, ocorre algo até pior, pois utilizam os guidelines propostos da mesma forma como são utilizados em estudos de outra procedência, sem que se dê conta da natureza diversa destas opções metodológicas distintas.

Nesta linha de raciocínio, Martin et al. ${ }^{17}$ ressaltam a preocupação pelo fato de se avaliarem artigos sustentando-se ainda com critérios quantitativos, de certa forma travestidos com roupagem qualitativa.

A natureza do Guia Rats não permite uma avaliação crítica sobre modos de fazer ciência, até porque não é seu objetivo. Todavia, um dos itens pouco considerados por autores e pareceristas refere-se ao autoquestionamento dos pesquisadores no que concerne ao exame crítico de sua própria influência na formulação do problema de pesquisa, no levantamento de dados e na interpretação dos resultados.

\section{Sobre modelos de pesquisa qualitativa e o problema da uniformização}

Um tema importante nas pesquisas qualitativas que, de certa forma, vem sendo esquecido, é o de que não existe "um modelo de entendimento" ou "um método compreensivo-interpretativo".

Falar sobre um método compreensivo-interpretativo implica, além de explicitar uma escolha consciente e deliberada, entender o que é compreensão e interpretação nas ciências sociais e humanas. Não se trata de palavras autoexplicativas, mas de referências conceituais profundas, relacionadas a certas escolas de pensamento. Da mesma maneira, não se pode afirmar que o processo interpretativo seja o mesmo para todas as pesquisas qualitativas. No caso da Antropologia, por exemplo, embora se defina como uma ciência interpretativa ${ }^{18}$, encontramos, nela, várias maneiras de interpretar que, por sua vez, estão relacionadas a uma matriz disciplinar com distintos enfoques teóricos.

Surge, então, um primeiro deslocamento conceitual importante para a avaliação de pesquisas qualitativas. Diante da diversidade de abordagens teóricas utilizadas nos artigos, tal como indicado por Deslandes e Iriart ${ }^{1}$, não se pode falar que se trata de um processo de sucessão, onde um paradigma sucederia a outro, invalidando-o ou tornando-o obsoleto. Muitas vezes subentendido em debates ou publicações científicas, este tipo de interpretação nada mais faz do que empobrecer as possibilidades de interpretação (entendidas aqui no seu sentido plural ou polissêmico) como desqualificar trabalhos valiosos. Há que se respeitar as diversas tradições intelectuais. Como afirmou Cardoso de Oliveira18: 
À diferença das ciências naturais, que os registram em sucessão - (os paradigmas) num processo contínuo de substituição -, na antropologia social os vemos em plena simultaneidade, sem que o novo paradigma elimine o anterior pela via das "revoluções científicas" de que nos fala Khun, mas aceite a convivência, muitas vezes num mesmo país, outras vezes numa mesma instituição. (p. 15)

Na ausência de crítica, corremos o risco de praticar apenas a apresentação de um jogo de conceitos, mais ou menos precisos em suas definições a priori, e instigar o leitor a aceitar o caminho certo, a rota precisa, a determinação. A que devemos tal reducionismo teórico e metodológico que imputa a certeza de que exista "um" método? Mais ainda, quem atribui a valoração que estabelece quais fenômenos seriam mais relevantes, e outros menos relevantes? Numa palavra: quem faz as escolhas?

Uma convicção expressa na ideia de existência de um único método deixa de apresentar outros modelos teórico-interpretativos e nos deixa, como leitores, sem saber os porquês desta escolha. Essência da própria pesquisa qualitativa e mesmo do campo das ciências sociais como um todo, é o posicionamento que tomamos, não por ingenuidade e, menos ainda, por desconhecimento. Conferir à afirmação de um único caminho teórico-metodológico a designação de impostura intelectual ${ }^{19}$ não parece conter qualquer exagero. Pelo contrário, carregada de sentido, tal impostura deixa de expor justamente aquilo que as pesquisas sociais têm de mais enriquecedor à reflexão: o conjunto de referenciais teórico-metodológicos construídos e transformados, desde o século XIX, que permitem observar fenômenos sociais de variados ângulos e que constituem as matrizes de pensamento na área de ciências sociais.

Uma rápida incursão pela sociologia compreensiva de orientação weberiana nos permite refletir sobre a possibilidade da produção de conhecimentos da sempre presente valoração imputada pelos sujeitos - aquele que observa e aquele cujas ações e pensamentos são observados nos processos de pesquisa. No limite, a afirmação de que: "não há uma metodologia, mas o exercício minucioso de uma criatividade que, longe de recuar diante dos desafios, nutre-se dos mesmos ao preço da renúncia à tranquilidade e ao conforto das conclusões definitivas" 20 (p. 38), parece conter muito do que queremos dizer em nossos processos de produção de conhecimento, desde que tenhamos clareza e façamos a exposição ampliada sobre nossas escolhas e a adesão a determinados valores que as orientam.

Autor de referência nas ciências sociais do século $X X$, em texto muito difundido nos meios de formação teórica para a pesquisa social, particularmente em sociologia, Wright Mills ${ }^{21}$ muito contribuiu para o ensinamento de uma característica fundamental à postura intelectual: a imaginação do pesquisador no que tange à produção de suas ideias e (por que não?) de suas ações enquanto pesquisador e, também, responsável pela difusão de conhecimentos por meio de seus escritos. A imaginação, diz-nos o autor, significa ter:

Consciência da ideia de estrutura social e utilizá-la com sensibilidade é ser capaz de identificar as ligações entre uma grande variedade de ambientes de pequena escala. Ser capaz de usar isso é possuir imaginação sociológica. ${ }^{21}$ (p.17)

Mills nos fala sobre as grandes questões públicas que, a seu ver, deveriam constituir as verdadeiras preocupações da sociologia. Em meados dos anos 1950, o autor apresentava uma crítica acirrada a modismos teóricos que permeavam as ciências sociais desde então. Nas suas palavras, essas "modas intelectuais configura(va)m conjuntos efêmeros que pouco contribuem para a construção e difusão de conhecimentos mais duradouros e que permitam o exercício de uma crítica mais ampliada às sociedades industrializadas ${ }^{21}$.

A imaginação sociológica é uma qualidade que compromete, aquele que investiga, ao entendimento das realidades menores e mais próximas e, muitas vezes, dentro de sua própria pessoa. Um entendimento que permite lançá-lo à ligação intelectual com realidades mais amplas, estruturas que cercam nossas vidas e constituem o conjunto de instituições que formam as sociedades complexas ${ }^{21}$. O autor denuncia determinados círculos que formam "corpos de técnicas burocráticas" cuja finalidade explícita é formular conhecimentos sobre o social, mas, simultaneamente, acabam 
por defender e divulgar conceitos obscuros que em nada contribuem para as questões de relevância pública ${ }^{21}$ (p. 27).

Acreditamos, portanto, que aceitar a ideia de uma metodologia de pesquisa qualitativa significa negar as inúmeras possibilidades de interpretação que os métodos qualitativos oferecem, inviabilizando, assim, sua especificidade e riqueza.

\section{Considerações inconclusas}

Apontamos alguns itens críticos na maneira como parte das pesquisas qualitativas tem sido produzida. Reconhecemos, todavia, que o desafio de entrar em áreas multidisciplinares, como é o caso da saúde coletiva, é também gratificante e provocativo para todos os que se reconhecem neste campo científico. Estamos sempre dialogando com outros campos semânticos, que, frequentemente, resultam em má interpretação ou incompreensão.

É possível que estes efeitos sejam decorrentes da proximidade com as outras áreas, mas, de qualquer modo, acabam incorporando categorias das ciências bionaturais ao âmbito das pesquisas qualitativas em saúde de maneira inapropriada. Muitas vezes, o desejo de homogeneizar pesquisas qualitativas compromete epistemologicamente a qualidade e o rigor, além de conduzir ao descrédito do que poderia acrescentar em termos de compreensão. Devemos nos preocupar em trazer, ao leitor, as informações necessárias para uma compreensão clara de nossos propósitos. Explorar a complexidade do método e das técnicas escolhidos, seus limites e possibilidades, os horizontes que alcançam e, sobretudo, desenvolver um sentido crítico para a produção científica nos moldes que hoje se nos apresenta, são algumas tarefas importantes.

Precisamos estar atentos a esta pretensão equivocada pela univocidade dos sentidos e sensibilizar a inteligência para outros horizontes, desconfiando das respostas rápidas. Este chamado a uma maneira de fazer ciência considera que sempre conhecemos de maneira tensa.

\section{Colaboradores}

Os autores trabalharam juntos em todas as etapas de produção do manuscrito. 


\section{Referências}

1. Deslandes SF, Iriart JAB. Usos teórico-metodológicos das pesquisas na área de ciências sociais e humanas em saúde. Cad Saude Publica. 2012; 28(12):2380-6.

2. Nakamura E. O método etnográfico em pesquisas na área da saúde: uma reflexão antropológica. Saude Soc. 2011; 20(1):95-103.

3. Victora CG. Uma ciência replicante: a ausência de uma discussão sobre o método, a ética e o discurso. Saude Soc. 2011; 20(1):104-12.

4. Nunes ED. Interdisciplinaridade: conjugar saberes. Saude em Debate. $2002 ; 26(62): 249-58$.

5. Gomes MHA. Apontamentos socioantropológicos sobre comunidade e saúde. Rev Saude Publica. 2006; 40(3):528-36.

6. Luz MT. Complexidade do campo da saúde coletiva: multidisciplinaridade, interdisciplinaridade, e transdisciplinaridade de saberes e práticas-análise sócio-histórica de uma trajetória paradigmática. Saude Soc. 2009; 18(2):304-11.

7. Canesqui AM. As ciências sociais, a saúde e a saúde coletiva In: Canesqui AM, organizadora. Dilemas e desafios das ciências sociais na saúde coletiva. São Paulo: Hucitec; 1995. p. 19-35. (Saúde em Debate, n. 92)

8. Martin D, Andreoli SB, Quirino J, Nakamura E. Noção de significado nas pesquisas qualitativas em saúde: a contribuição da antropologia. Rev Saude Publica. 2006; 40(1):178-80.

9. Gomes MHA, Silveira C. Sobre o uso de métodos qualitativos em Saúde Coletiva, ou a falta que faz uma teoria. Rev Saude Publica. 2012; 46(1):160-5.

10. Loyola MA. O lugar das ciências sociais na saúde coletiva. Saude Soc. 2012; 21(1):9-14

11. Bosi MLM. Pesquisa qualitativa em saúde coletiva: panorama e desafios. Cienc Saude Colet. 2012; 17(3):575-86.

12. Minayo MCS. A produção de conhecimentos na interface entre as ciências sociais e humanas e a saúde coletiva. Saude Soc. 2013; 22(1):21-31.

13. Maingueneau D. Novas tendências em análise do discurso. 3a. ed. Campinas: Ed. Universidade Estadual de Campinas; 1997.

14. Carvalho MS, Travassos C, Coeli CM. Um bom texto. Cad Saude Publica. 2013; 29(9):1701.

15. Castiel LD, Sanz-Valero J, Red Mel-CYTED. Entre fetichismo e sobrevivência: o artigo científico é uma mercadoria acadêmica? Cad Saude Publica. 2007; 23(12):3041-50.

16. Clark JP. The RATS guidelines modified for BioMed Central. How to peer review a

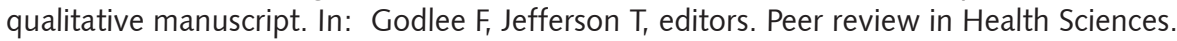
2nd. ed. London: BMJ Books; 2003. p. 219-35.

17. Martin D, Andreoli SB, Pinto RMF, Barreira TMHM. Sobre fazer ciência na pesquisa qualitativa: um exercício avaliativo. Rev Saude Publica. 2012; 46(2):392-3.

18. Cardoso de Oliveira R. Sobre o pensamento antropológico. Rio de Janeiro: Tempo Brasileiro; 1988.

19. Sokal A, Bricmont J. Imposturas intelectuais. Rio de Janeiro: Record; 1999.

20. Lazarte R. Max Weber: ciência e valores. Cortez: São Paulo; 1996.

21. Mills CW. A imaginação sociológica. 2a. ed. Rio de Janeiro: Zahar; 1969. 
Gomes MHA, Martin D, Silveira C. Comentarios pertinentes sobre usos de metodologías cualitativas en salud colectiva. Interface (Botucatu). 2014; 18(50):469-77.

Con este texto nuestro objetivo es contribuir para el debate sobre la evaluación de la producción y de la divulgación de investigaciones basadas en metodologías cualitativas en salud colectiva. Buscamos relacionar las brechas teóricas y metodológicas con indicios de valoración que están presentes en los procesos de investigación y evaluación de artículos publicados. En la ausencia de explicación de los valores que llevaron a las opciones mostradas en las investigaciones, algunos periódicos recomiendan recursos de valoración que privilegian procedimientos formales y técnicos. La valoración se complementa con guías de elaboración de artículos, entre los cuales las check-lists, que proporcionan los ítems evaluados. Estos factores contribuyen para reduccionismos teórico-metodológicos y refuerzan la creencia en la existencia de un único método. Finalmente, renovamos la llamada a la imaginación y a la diversidad de concepciones sobre lo que pretendemos conocer.

Palabras clave: Metodologías de investigación cualitativa. Evaluación por pares. Salud colectiva. Ciencias sociales y humanas.

Recebido em 30/04/14. Aprovado em 09/05/14 
